\title{
INSTITUCIONALIZAÇÃO DE POLÍTICAS PÚBLICAS DE PROMOÇÃO DA IGUALDADE DE GÊNERO: SISTEMATIZANDO TRAJETÓRIAS DE INICIATIVAS NACIONAIS E INTERNACIONAIS
}

\author{
D. C. Momo, J. A. Paiva, A. S. C. Ribeiro, B. L. D. Cardoso e W. J. Souza \\ Universidade Federal do Rio Grande do Norte \\ denisecmomo@yahoo.com.br-juarez.paiva@ig.com.br-abdon_ribeiro@yahoo.com.br- \\ brunoluan.dc@hotmail.com-wsouza@ufrnet.br
}

Artigo submetido em março/2013 e aceito em março/2013

\section{RESUMO}

A experiência da mulher na esfera privada no âmbito do trabalho altera relações intrafamiliares, permitindo-Ihes maior liberdade, autonomia e independência. As desigualdades, socialmente construídas, de interiorização do papel da mulher, por sua vez, redundam em discriminações, e dificuldades de sua inserção no mercado de trabalho, com salários inferiores em relação aos do homem, e dificuldades de acesso a serviços, além de cotidiano penoso no âmbito da esfera doméstica. As ações governamentais, as políticas públicas e os programas desenvolvidos pelos governos federais, estaduais e municipais, no âmbito das relações de gênero, são, assim, relevantes na amenização das desigualdades. É este, pois, o objeto do presente texto, que discute a institucionalização de políticas públicas para a construção da igualdade de gênero e a relevância que assume o Estado no papel de incorporar e provocar o viés das relações de gênero em ações e debates públicos. No Brasil, a formulação e implementação do Plano Nacional de Políticas para Mulheres foi, nesse sentido, de fundamental importância para balizar ações a serem desenvolvidas pelos governos no fomento a iniciativas de igualdade nas relações entre homens e mulheres.

PALAVRAS-CHAVE: Estado, Desigualdade de Gênero, Plano Nacional de Políticas para Mulheres.

\section{INSTITUTIONALIZATION OF PUBLIC POLICIES THE PROMOTING GENDER EQUALITY: SYSTEMATIZING TRAJECTORIES OF NATIONAL AND INTERNATIONAL INITIATIVES}

\begin{abstract}
The experience of women in the private sphere in the work alters intra-family relationships, allowing them greater freedom, autonomy and independence. Inequalities, socially constructed, of internalization of the role of women, in turn, result in discrimination, integration difficulties market, with salaries comparatively inferior to man, and poor access to services, plus painful daily within the sphere domestica. Public policies actions and programs developed by federal, state and local goverment, as part of gender
\end{abstract}

relations, are thus relevant in reducing inequalities. This is, then, the object of this text, which discusses the institutionalization of public policies for the construction of gender equality and the relevance that the state assumes the role of incorporating the bias and cause of gender relations in public debates and actions. In Brazil, the formulation and implementation of the National Policy for Women was, in this sense, crucial to guide actions to be taken by governments in fostering equality initiatives in relations between men and women.

KEY-WORDS: State, Gender Inequality, National Plan of Policies for Women. 
INSTITUCIONALIZAÇÃO DE POLÍTICAS PÚBLICAS DE PROMOÇÃO DA IGUALDADE DE GÊNERO: SISTEMATIZANDO TRAJETÓRIAS DE INICIATIVAS NACIONAIS E INTERNACIONAIS

\section{INTRODUÇÃO}

Este texto objetiva sistematizar trajetórias de iniciativas nacionais e internacionais relativas à institucionalização de políticas públicas para a promoção da igualdade de gênero. A formulação e implementação de políticas públicas voltadas ao campo das relações de gênero exige, necessariamente, o reconhecimento de que as desigualdades entre mulheres e homens têm raízes culturais e, que, não obstante os inegáveis avanços que asseguram cada vez mais os direitos das mulheres, tem-se, ainda, um longo caminho a trilhar no Brasil e no mundo, o que demanda compromissos, participação ativa e controle de organizações governamentais e não governamentais - da sociedade civil. Está explícito, então, que os momentos democráticos de preparação para reflexão, elaboração e avaliação de políticas públicas, que culminam na tomada de decisões em conferências, transcorrem pelo campo da gestão social, pois, além da exigência de representações de órgãos dos poderes públicos, requerem mobilização de movimentos sociais e de organizações da sociedade civil, pela via da participação e do exercício do controle social.

A complexidade do conceito de gênero vai além da justificativa ideológica da reprodução simbólica, na construção do masculino e do feminino, pois, faz parte das lutas da organização feminista, que buscam compreender como se dão as desigualdades do trabalho entre homens e mulheres. Essas desigualdades podem ser vistas no acúmulo de atividades desempenhadas pelas mulheres quando entram no mercado de trabalho, uma vez que continuam com a responsabilidade dos trabalhos domésticos e dos cuidados com a família. Historicamente, como demonstra Faria (2010), as desigualdades têm base em construção ideológica a partir de uma identidade focada na ideia de que o papel principal da mulher é ser uma boa mãe e sua realização se dá por meio dos afazeres domésticos e de práticas de cuidados.

O conceito de gênero, conforme Simone de Beauvoir, foi construído ao longo da história pela sociedade, passando-se ao entendimento de que a mulher não nasce mulher, mas, sim, se torna mulher, e, o homem, não nasce homem, mas, sim, torna-se homem. As diferenças no modo de ser, pensar e fazer entre homens e mulheres passam por aspectos culturais cujos sujeitos estão imersos desde o nascimento. É nas relações sociais, impostas pelo mundo preexistente ao sujeito, que se aprende a pensar que a mulher é movida pela emoção e o homem pela razão. Portanto, é o meio social quem define as qualidades do masculino e do feminino, que diz o que é ser homem e ser mulher e que tipo de papel e de trabalho cada um deve desempenhar. A predominância do entendimento desse conceito se dá, portanto, em aspectos culturais e não biológicos (CAROLA, 2002).

Hoje em dia as mulheres continuam enfrentando desigualdades no mercado de trabalho, conforme dados do Instituto de Pesquisa Econômica Aplicada (IPEA). No ano de 2007, houve um aumento expressivo na proporção de famílias chefiadas por mulheres, passando de $24,9 \%$, em 1997, para 33\%, em 2007, o que representa um total de 19,5 milhões de famílias brasileiras que identificam a mulher como principal responsável pela família. Outros dados do Instituto Brasileiro de Geografia e Estatística (IBGE) mostram que, em 2007, 50,5\% dos homens ocupados afirmaram cuidar dos afazeres domésticos, contra $89,6 \%$ das mulheres ocupadas. Esses resultados demonstram que as mulheres, predominantemente, enfrentam duplas jornadas de trabalho, ficando responsáveis pela maioria das tarefas domésticas, além do trabalho remunerado fora de 
casa, ainda que, nos dias atuais, existam avanços na colaboração do homem no trabalho doméstico.

O enfrentamento das desigualdades de gênero e a busca pela igualdade entre homens e mulheres fazem parte do processo histórico de lutas das mulheres no Brasil, história construída por diferentes mulheres, em diferentes espaços, de diferentes maneiras. Tanto no espaço privado, representado pelo trabalho doméstico e de cuidados dos familiares, quanto na esfera pública, representada pelo mercado de trabalho, as mulheres vêm questionando e buscando novos espaços, alterando gradativamente as relações de poder e a rígida divisão sexual de trabalho.

A análise das trajetórias das mulheres demonstra mudanças do que é ser mulher no princípio do século XXI, a partir da conquista do controle do corpo, no controle da natalidade, traduzindo importante ruptura na ideologia da responsabilidade da mulher somente na esfera privada, representada na domesticidade. As gerações atuais vêm conquistando novos espaços no mercado de trabalho, o que deverá ter repercussões nas gerações futuras. As mulheres estão se inserindo no mundo da cultura, da política e dos negócios, e essa inserção está feminilizando as relações sociais a partir de vivências e posicionamentos que permitem novas perspectivas na construção de relações em espaços de participação, controle social e gestão pública.

O papel do Estado é, nesse sentido, de fundamental importância na elaboração de políticas públicas que venham a contemplar a equidade de gênero, pois, é de sua responsabilidade a promoção de mudanças das desigualdades sociais. É necessário levar em consideração a responsabilidade educativa do Estado, uma vez que suas ações decorrem de valores, relações e comportamentos socialmente compartilhados e pactuados. Portanto, como advoga Godinho (2004), as ações do governo não podem ser vistas de maneira isolada, ou seja, devem ser coerentes com o projeto geral de mudança em que as desigualdades de gênero sejam componentes indispensáveis e inegociáveis.

Além de ser o Estado responsável por fomentar e implementar políticas públicas que possam diminuir desigualdades de gênero, ele é igualmente responsável pela dimensão da reformulação de preceitos, viabilizando ações socioeducativas transversais, que venham a valorizar a força de trabalho feminino perante a sociedade, bem como a desconstruir a cultura discriminatória que submete as mulheres a condições de desigualdade. O Estado, portanto, deve criar espaços nos diversos segmentos sociais, inclusive na esfera institucional, questionando e induzindo práticas, políticas e novas formas que visualizassem maior equidade de gênero.

As políticas públicas voltadas para a construção da equidade devem ter a preocupação em enfrentar os eixos centrais que constroem as desigualdades no cotidiano das mulheres, ou seja, as desigualdades na divisão sexual do trabalho na esfera privada e pública, a restrita autonomia econômica e do corpo e a sexualidade, além de outros como racismo e preconceitos. A formulação e a implementação de políticas públicas, assim, atendem à Constituição brasileira, promulgada em 1988, quando afirma que homens e mulheres são iguais entre si, em direitos e obrigações e, assim, garante tratamento igual perante a Lei conforme reza o Capítulo I - Dos Direitos e Deveres Individuais e Coletivos, Art. 5ำ, parágrafo 1ㅇ․

A elaboração do Plano Nacional de Políticas para Mulheres, todavia, ocorreu tempos depois. Ela é responsável por delinear diretrizes para uma política nacional para as mulheres, fruto da I Conferência Nacional de Políticas para as Mulheres, realizada em Brasília, em 2004. Esse evento foi antecedido por plenárias municipais e regionais e Conferências Estaduais, permitindo a participação de mulheres de todo o país e traduzindo representatividade e 
consistência das propostas em pauta. Iniciativas em sentido similar encontram-se nos primeiros documentos de proteção internacional dos direitos humanos, a Carta das Nações Unidas, de 1945, e a Declaração Universal de Direitos Humanos, de 1948, que traduzem ideias de que homens e mulheres devem ser tratados de maneira igual na sociedade.

Para tratar desse tema, o presente texto está assim estruturado: no tópico seguinte, discute-se o tema desigualdade de gênero vinculando-o à emergência de iniciativas de institucionalização do tema em nível internacional. Após resgate de momentos relevantes do tema no cenário mundial, a partir de iniciativas das Organizações das Nações Unidas (ONU), aborda a trajetória brasileira, iniciada em 2003, a partir da criação da Secretaria Especial de Políticas para Mulheres da Presidência da República (SEPM/PR). Nas reflexões finais, é destacado o fato de que as ações governamentais, através de políticas públicas e programas desenvolvidos pelo Estado, podem exercer papel fundamental na redução do quadro de desigualdades, desde que, dentre outros fatores, o poder público reconheça que as desigualdades existem e que é seu papel fomentar iniciativas para a promoção da equidade de gênero.

\section{DESIGUALDADE E POLÍTICAS PÚBLICAS PARA A EQUIDADE DE GÊNERO}

As desigualdades de gênero são refletidas na sociedade brasileira em pequenas e grandes discriminações, em pequenas e grandes dificuldades enfrentadas pelas mulheres no cotidiano, na dificuldade de inserção no mercado de trabalho, na dificuldade de acesso a serviços, na dupla jornada entre o trabalho na esfera doméstica e na esfera pública, entre outras. Em 2003, a diferença entre homens e mulheres com carteira assinada era de $24,7 \%$, caindo, no ano de 2011 , para 19,1\%. O maior crescimento da participação feminina ocorreu, no período, nos empregos sem carteira assinada no setor privado. A Pesquisa Mensal de Emprego do IBGE, de 8 de março de 2012, em comemoração ao Dia Internacional da Mulher, fez uma análise da posição desta no mercado de trabalho, demonstrando que, apesar de terem sido diminuídas as desigualdades das mulheres em relação aos homens, o rendimento delas continua inferior. No ano de 2011 , as mulheres recebiam, em média, $72,3 \%$ do salário dos homens, tendo sido mantido esse percentual inalterado por três anos, desde 2009. As diferenças de inserção entre homens e mulheres no mercado de trabalho foram reduzidas, todavia, no ano de 2011, com aumento da participação em todas as formas de ocupação.

Conforme assinala Godinho (2004), é de reponsabilidade do Estado a preservação qualitativa das relações sociais estabelecidas na sociedade e, por outro lado, a contenção dos conflitos gerados por eventual tecido social discriminatório. O Estado é responsável pela construção da igualdade de gênero, tanto na regulação das leis que venham coibir a discriminação quanto como articulador de mudanças culturais nas condições de vida das mulheres, propondo políticas públicas que venham a incorporar as dimensões de gênero e raça, dentre outras. Dessa forma, no caso das políticas voltadas para a igualdade de gênero, é relevante que estas abordem problemas centrais que constroem as desigualdades, ou seja, que considerem "[...] a falta de autonomia pessoal e econômica, a desigualdade na divisão sexual do trabalho, na família, a autonomia do corpo e a sexualidade, o racismo e os preconceitos e 0 rompimento com o silêncio e a invisibilidade das vozes das mulheres" (SOARES, 2004, p. 117).

Objetivando a uma melhor visualização dos problemas da desigualdade de gênero abordados pelo autor, o Quadro abaixo sintetiza os cinco problemas centrais por ele retratados e as respectivas abordagens: 
Quadro 1 - Problemas Centrais na Desigualdade de Gênero.

\begin{tabular}{|c|c|}
\hline $\begin{array}{l}\text { Problemas Centrais da } \\
\text { Desigualdade de Gênero }\end{array}$ & Abordagens \\
\hline $\begin{array}{l}\text { Restrita autonomia pessoal e } \\
\text { econômica }\end{array}$ & $\begin{array}{l}\text { A independência econômica é fator primordial na emancipação } \\
\text { das mulheres, ou seja, por meio dela a mulher adquire direito à } \\
\text { cidadania. O crescimento da presença das mulheres no } \\
\text { mercado de trabalho, nas últimas décadas, é extremamente } \\
\text { relevante, mas, ainda se realiza em condições desiguais. As } \\
\text { mulheres estão ingressando nos trabalhos sem proteção e com } \\
\text { menores salários. }\end{array}$ \\
\hline $\begin{array}{l}\text { Divisão sexual do trabalho e } \\
\text { na família }\end{array}$ & $\begin{array}{l}\text { As relações desiguais de gênero são, ainda, sustentadas pela } \\
\text { divisão sexual e diferenciadas do trabalho, tanto no âmbito da } \\
\text { esfera privada quanto na esfera pública. Na esfera privada, a } \\
\text { mulher é responsável pelo trabalho doméstico e de cuidado dos } \\
\text { filhos e demais familiares (trabalho não remunerado), enquanto } \\
\text { que o homem é responsável pela esfera privada (mercado de } \\
\text { trabalho remunerado). }\end{array}$ \\
\hline $\begin{array}{c}\text { Autonomia do corpo e } \\
\text { sexualidade }\end{array}$ & $\begin{array}{l}\text { O controle do corpo das mulheres e a imposição da } \\
\text { maternidade são formas constitutivas da identidade feminina, } \\
\text { no processo de subordinação das mulheres pela sociedade. Por } \\
\text { isso, o movimento de mulheres tem atuado para a construção } \\
\text { da autonomia e do direito de autodeterminação. As políticas } \\
\text { públicas de combate à violência doméstica e sexual e de } \\
\text { garantia do direito à saúde e ao exercício dos direitos sexuais e } \\
\text { reprodutivos têm papel primordial nessa abordagem. }\end{array}$ \\
\hline $\begin{array}{c}\text { Combate ao racismo e aos } \\
\text { preconceitos }\end{array}$ & $\begin{array}{l}\text { O racismo e o sexismo são duas formas fundamentais de } \\
\text { discriminação que perpassam a sociedade em todas as relações } \\
\text { sociais no Brasil. Gênero e raça são eixos estruturantes dos } \\
\text { padrões de desigualdade e exclusão sociais. Esse combate deve } \\
\text { está alinhado às desigualdades e à descriminação de gênero e } \\
\text { raça. }\end{array}$ \\
\hline $\begin{array}{l}\text { Rompimento do silêncio e da } \\
\text { invisibilidade das mulheres }\end{array}$ & $\begin{array}{l}\text { Este problema exige, também, favorecer a organização e a } \\
\text { participação das mulheres, não individualmente, mas, como } \\
\text { sujeito coletivo, mulheres sujeitos de direitos. Ou seja, é preciso } \\
\text { reforçar a expressão política da mulher para assegurar seus } \\
\text { pontos de vista, garantindo que suas demandas sejam } \\
\text { consideradas nos espaços públicos e nas relações privadas. }\end{array}$ \\
\hline
\end{tabular}

Fonte - Elaborado pelos autores com base em Soares (2004, p.117-118).

A elaboração de políticas de enfrentamento aos problemas centrais da desigualdade traz relevantes conquistas à realidade de homens e mulheres. Tais políticas evidenciam o reconhecimento da realidade de homens e mulheres e, implementar políticas públicas para a equidade de gênero significa construir esforços para redistribuir, de forma mais justa, os recursos públicos, entre homens e mulheres, por meio de reformas legais que contemplem programas e serviços que permitam o acesso igualitário aos recursos econômicos, da educação, da cultura e da pesquisa (SOARES, 2004). As políticas públicas possuem papel transformador no atendimento a demandas sociais, e, dessa forma, no que se refere ao tema da equidade de gênero, favorece ao exercício da cidadania e à mudança cultural. As políticas públicas nesse campo, portanto, 
devem contemplar meios que possibilitem às mulheres o atendimento de outros papéis sociais, além daquele relativo ao de dona-de-casa, mãe de família, esposa e outros encargos na esfera doméstica. Devem ser pensadas políticas sociais que venham a refletir na qualidade de vida de todos os membros da família.

O desenvolvimento de políticas públicas para mulheres está marcado por processos históricos de conquistas e de mudanças socioculturais. O Novo Feminismo surgiu na década de 1960, trazendo em suas discussões o questionamento dos papéis tradicionais de homens e mulheres, na sociedade, tanto no âmbito da esfera privada (doméstica) quanto da esfera pública (mercado) (FUJIWARA, 2002). Segundo Heilborn (1995), o Novo Feminismo marca uma revolução na cultura contemporânea, de modo que, os anos 1960 podem ser chamados de "década da contestação", pois, além da luta pela emancipação das mulheres, aglutinou outros fenômenos como o movimento hippie, as pressões de minorias na busca de direitos civis, a popularização de drogas, a busca por novas formas de vida comunitária e o pacifismo, com indícios de uma reviravolta na dominação da sociedade burguesa no século XX.

O resultado do crescimento e da disseminação do feminismo, como processo subsequente, tornou o ano de 1975 conhecido como Ano Internacional da Mulher, através de declaração da Organização das Nações Unidas (ONU), cujo intuito foi demonstrar o reconhecimento das desigualdades de gênero entre homens e mulheres, além de incentivar a inserção da temática da mulher nos organismos internacionais (HEILBORN, 1995). Entre os anos 1970 e 1980, as mulheres passaram a sair do espaço privado, iniciando movimentos de atuação e mobilização na esfera pública, ou seja, pautaram discussões públicas de temas como sexualidade, aborto, direitos à cidadania, violência intrafamiliar, dentre outros. $\mathrm{O}$ tema da sexualidade, por exemplo, até então considerado de pouca importância política e social, é trazido para o campo político, na discussão em torno de pressupostos hierárquicos que regem as representações sexuais das mulheres e as definições do lícito e do ilícito para toda a sociedade (RAGO, 2001).

No Brasil, a institucionalização da relação do Estado com o movimento de mulheres ocorre na década de 1980, por meio da mobilização das mulheres no processo de redemocratização. As primeiras políticas públicas com foco em gênero surgiram em 1983, com a criação dos primeiros conselhos estaduais de Direitos da Mulher e da Condição Feminina, na forma de órgão colegiado com representação do movimento feminista. Em 1985, foi instalada a primeira Delegacia de Política de Defesa da Mulher, no Estado de São Paulo. Essas iniciativas foram socializadas e institucionalizadas rapidamente nos demais estados. Também no ano de 1985, após mais de uma década de mobilização do movimento feminista e latino-americano, foi criado o Conselho Nacional dos Direitos da Mulher (CNDM), órgão institucionalmente vinculado ao Ministério da Justiça que responde diretamente ao Gabinete da Presidência da República (FARAH, 2004).

A criação do CNDM é fruto de um vasto trabalho de mobilização e luta do movimento de mulheres. No ano de 1984, em São Paulo, no seminário intitulado Política e Mulher, surgiu a discussão sobre a criação de um fórum nacional de articulação na defesa dos direitos das mulheres. Após esse encontro, a Deputada Ruth Escobar organizou uma comissão responsável por fomentar, junto ao Governo Tancredo Neves em Minas Gerais, a institucionalização de um órgão representativo das mulheres junto aquele governo estadual, com o intuito de criar políticas públicas na igualdade de gênero (ROCHA, 2009). No ano seguinte, em 1985, foi atendida, em nível nacional, histórica reivindicação das mulheres através da criação do Conselho Nacional dos Direitos da Mulher (Lei $N^{\circ}$ 7.353, de 29 de agosto de 1985), que surgiu com a finalidade de: 
[...] promover em âmbito nacional, políticas públicas voltadas para e eliminação de todas as formas de discriminação contra a mulher, assegurando-Ihe condições de liberdade e de igualdade de direitos, bem como sua plena participação nas atividades políticas, econômicas e socioculturais do País (FUJIWAKA, 2002, p. 47).

Essa lei abrangeu a criação de um Fundo Especial de Direito da Mulher com o intuito de disponibilizar recursos ao CNDM, possibilitando o desenvolvimento de políticas e programas para a igualdade de gênero. O CNDM foi então estruturado com um Conselho Deliberativo, uma Assessoria Técnica e uma Secretaria Executiva (ROCHA, 2009). A criação do CNDM teve como principal ação política a discussão nacional articulada para definir a agenda das mulheres no processo constituinte que estava sendo iniciado. O Conselho alcançou resultados importantes, através de intensa mobilização social, os quais podem ser constatados na Carta Magna de 1988 no tocante à igualdade de gênero e aos direitos da mulher. A Constituição estabeleceu normatização de igualdade no âmbito da sociedade conjugal de homens e mulheres, reconhecimento da violência intrafamiliar como responsabilidade de governo, e do direito à livre escolha, no tocante à reprodução, aqui avançando na garantia de direitos para a mulher no âmbito do trabalho, na esfera do trabalho doméstico, na condição da mulher rural, no aumento do prazo da licença-maternidade de 90 para 120 dias e na instituição da licença paternidade de cinco dias (OIT, 2010).

Os anos 1990 foram marcados pelo reconhecimento da importância da criação de políticas públicas para mulheres. Em 1995, durante a IV Conferência Mundial da Mulher, realizada na China, na cidade de Pequim, a comunidade internacional reconheceu que tanto a igualdade de gênero quanto as pautas culturais a ela inerentes são condicionadas por políticas públicas. Foram definidas, assim, na Conferência, duas estratégias para alcançar a igualdade de gênero:

[...] a transversalidade em todos os processos de tomadas de decisões e o empoderamento das mulheres, entendido como a autoafirmação das capacidades das mulheres para sua participação, em condições de igualdade, nos processos de tomadas de decisões e de acesso ao poder (PEREIRA, et al., 2010, p. 425).

Além dessas iniciativas, na IV Conferência Mundial da Mulher, foi igualmente defendida a adoção de medidas para abranger o tema de gênero nos orçamentos públicos, incluindo estratégias de financiamento para programas específicos de fomento à promoção da igualdade de gênero. Dessa forma, o evento internacional reconheceu o papel relevante que assumem Estados e governos das várias nações do mundo na superação de entraves que se encontram postos à formulação de políticas públicas para lidar com a condição de subalternidade em que vive a mulher. O Brasil, na condição de signatário do documento final resultante dos debates daquele encontro, iniciou, na década seguinte, uma trajetória de institucionalização de políticas públicas para mulheres.

\section{TRAJETÓRIA DAS INICIATIVAS BRASILERIAS}

No Brasil, o ano de 2003 foi marcado pela criação da Secretaria Especial de Políticas para Mulheres da Presidência da República (SEPM/PR), em 10 de janeiro de 2003, com status de Ministério. Estreia, assim, um novo momento de articulação, formulação e coordenação de políticas públicas de fomento à igualdade de gênero. Ficaram sob a responsabilidade da SEPM, 
ainda, o planejamento, a elaboração e a efetivação de campanhas educativas antidiscriminatórias contra a mulher, no intuito de promover ações do Governo Federal e demais esferas de governo, para a promoção da igualdade de gênero (SEPM, 2012).

Foi, então, realizada entre 15 e 17 de julho de 2004, em Brasília, a I Conferência Nacional de Políticas para Mulheres, através de convocação do Presidente da República. O processo de articulação e organização envolveu cerca de 120 mil mulheres, que participaram ativamente das plenárias estaduais, municipais e regionais, realizadas em todo o país. As deliberações da Conferência subsidiaram a elaboração do Plano Nacional de Políticas para as Mulheres (PNPM) e, hoje, é documento norteador no desenvolvimento de políticas públicas para mulheres pelo Governo Federal e demais esferas (PNPM, 2005). A Secretaria Especial de Políticas para as Mulheres e o Conselho Nacional dos Direitos da Mulher (CNPM) foram responsáveis por coordenar a Conferência, com a participação de representantes dos poderes executivos das esferas municipais e estaduais, diversos ministérios e secretarias especiais, além de intelectuais e acadêmicos do campo das causas feministas e organizações de mulheres.

Durante a Conferência, ocorreu o processo de construção de diretrizes para uma Política Nacional para Mulheres, a partir de discussões do documento-base "Propostas de Diretrizes para uma Política para as Mulheres". Nos vinte grupos de trabalho formados durante o evento foram discutidos temas como natureza, princípios e diretrizes para uma Política Nacional para mulheres, na concepção da igualdade de gênero, considerando as diversidades de etnia e raça. 0 documento foi organizado em cinco eixos temáticos: a) enfrentamento da pobreza: geração de renda, trabalho, acesso ao crédito e à terra; b) superação da violência contra a mulher: prevenção, assistência e enfrentamento; c) promover o bem-estar e qualidade de vida para as mulheres: uso e ocupação do solo, saúde, moradia, infraestrutura, equipamentos sociais, recursos naturais, patrimônio histórico e cultural; d) efetivação dos direitos humanos das mulheres: civis, políticos, direitos sexuais e direitos reprodutivos; e) desenvolvimento de políticas de educação, cultura, comunicação e produção de conhecimento para a igualdade (PINTO, 2006).

A elaboração do Plano Nacional de Políticas para Mulheres teve início com o Decreto Presidencial de 15 de julho de 2004, quando foi constituído Grupo de Trabalho Interministerial (GTI), com representação de sete Ministérios - Saúde; Educação; Trabalho e Emprego; Justiça; Desenvolvimento Agrário; Desenvolvimento Social; Planejamento, Orçamento e Gestão - e das Secretarias da Mulher do Estado do Acre e do Município de Campinas/SP, da Secretaria Especial de Políticas de Promoção da Igualdade Racial (SEPPIR) e do CNDM, sob a coordenação da Secretaria Especial de Políticas para Mulheres. Além das demandas surgidas nas discussões dos grupos de trabalho da I Conferência, foram incluídas, no PNPM, metas próprias de interesse do Governo Federal (PINTO, 2006).

O Governo Federal ficou com a responsabilidade de divulgar o Plano junto aos estados e municípios e, também, de revisar e atualizar as diretrizes da PNPM, de acordo com as discussões políticas ocorridas na I Conferência Nacional de Políticas para Mulheres, que passou a ser realizada a cada três anos, sempre articulada por meio de conferências antecedentes estaduais, municipais e no Distrito Federal (PINTO, 2006). "As ações do Plano foram traçadas a partir de quatro linhas de atuação, consideradas como as mais importantes e urgentes para garantir, de fato, o direito a uma vida melhor e mais digna para todas as mulheres" (PNPM, 2005, p.13). São elas: a) autonomia, igualdade no mundo do trabalho e cidadania; b) educação inclusiva e não sexista; c) saúde das mulheres, direitos sexuais e direitos reprodutivos; d) enfrentamento da violência contra as mulheres (PNPM, 2006). 
O Quadro 2 sintetiza a repercussão do I PNPM entre os estados, tomando como base o número de municípios que aderiu à iniciativa. Nele, sem maiores esforços, fica nítida a restrita adesão dos municípios, indicando, a princípio, que o tema não despertou interesse entre gestores públicos das unidades federativas. No cômputo total, $5,6 \%$ do total de municípios integraram-se à iniciativa. Os estados onde ocorreram maiores adesões municipais foram Amapá $(68,8 \%)$ e Amazonas (54,8\%), ao passo que, no estado brasileiro com maior número de municípios - Minas Gerais - esse percentual alcançou 0,7\% do total. Situação de restrita adesão reproduz-se, ainda que em percentuais superiores, nos dois outros estados com maior número de municípios: São Paulo (8,4\%) e Rio Grande do Sul (3,2\%).

Quadro 2 - Adesão ao I Programa Nacional de Política para Mulheres 2005 a 2010.

\begin{tabular}{|c|c|c|c|}
\hline Estado da Federação & $\mathbf{N}^{\circ}$ de Municípios & Adesão ao PNPM & Percentagem (\%) \\
\hline Acre & 22 & 5 & 22,7 \\
\hline Alagoas & 102 & 17 & 16,7 \\
\hline Amazonas & 62 & 34 & 54,8 \\
\hline Amapá & 16 & 11 & 68,8 \\
\hline Bahia & 417 & 7 & 1,7 \\
\hline Ceará & 184 & 14 & 7,6 \\
\hline Distrito Federal & 1 & 0 & 0,0 \\
\hline Espírito Santo & 78 & 20 & 25,6 \\
\hline Goiás & 246 & 4 & 1,6 \\
\hline Maranhão & 217 & 4 & 1,8 \\
\hline Minas Gerais & 853 & 6 & 0,7 \\
\hline Mato Grosso do Sul & 78 & 17 & 21,8 \\
\hline Mato Grosso & 141 & 12 & 8,5 \\
\hline Pará & 143 & 2 & 1,4 \\
\hline Paraíba & 223 & 2 & 0,9 \\
\hline Pernambuco & 185 & 5 & 2,7 \\
\hline Piauí & 224 & 1 & 0,4 \\
\hline Paraná & 399 & 22 & 5,5 \\
\hline Rio de Janeiro & 92 & 18 & 19,6 \\
\hline Rio Grande do Norte & 167 & 3 & 1,8 \\
\hline Rondônia & 52 & 4 & 7,7 \\
\hline Roraima & 15 & 0 & 0,0 \\
\hline Rio Grande do Sul & 496 & 16 & 3,2 \\
\hline Santa Catarina & 293 & 10 & 3,4 \\
\hline Sergipe & 75 & 21 & 28,0 \\
\hline São Paulo & 645 & 54 & 8,4 \\
\hline Tocantins & 139 & 1 & 0,7 \\
\hline Total & 5565 & 310 & 5,6 \\
\hline
\end{tabular}

Fonte - Elaborado pelos autores com base em informações do PNPM (2012) e do IBGE, quanto ao número de municípios de cada estado (2010).

Não é possível, aqui, indicar motivos que expliquem tal descompasso. Interessa, todavia, registrar que o apelo não alcançou todos os estados em quantidade análoga e desejável, e, ainda, que o percentual total de municípios alcançou percentual mínimo quando se considera a situação geral da mulher e das relações de gênero em todo o território nacional. Os percentuais pouco expressivos refletem, em certa medida, indiferença dos municípios em institucionalizar ou 
reconhecer a pertinência de políticas públicas voltadas à equidade de gênero, retratando, ainda, restrita aderência em nível subnacional a necessidades, nacionalmente compartilhadas, e a interesses, esforços e investimentos do Governo Federal.

As adesões foram fomentadas através de termos de compromisso, no formato de pacto entre os governos dos municípios e a Secretaria de Políticas para as Mulheres (SPM), por meio de ações articuladas em eventos nos quais foi apresentado o Plano para autoridades governamentais e movimentos sociais de mulheres. Após as adesões, as esferas subnacionais tiveram o apoio da SPM na criação de secretarias, superintendências ou coordenadorias da mulher que deveriam se vincular diretamente ao gabinete do governador(a) ou prefeito(a).

Assim, ocorreram pactos em torno do Plano junto a estados e municípios que passaram a firmar parcerias com o Governo Federal e com movimentos sociais, de certo modo, avançando em ações voltadas para as mulheres.

Em 2007, foi realizada a II Conferência Nacional de Políticas para Mulheres. O evento aconteceu no período de 17 a 20 de agosto, no Centro de Convenções, em Brasília. As mulheres reuniram-se, desta vez, com o objetivo de avaliar o I Plano Nacional de Políticas para Mulheres e discutir a participação das mulheres nos espaços de poder, por meio de experiências brasileiras e experiências internacionais. O Congresso teve representação de 2.559 delegadas, através de eleições em 600 conferências municipais, estaduais, regionais e distrital. No Congresso Nacional, local onde ocorreu o evento, duas plenárias aprovaram, respectivamente, o regulamento do II CNPM, as prioridades dos cinco eixos do I PNPM e a criação de seis novos eixos para a II PNPM. Aprovaram, ainda, 33 moções e 28 recomendações. Em pauta, portanto, estavam:

\footnotetext{
Seis novos eixos: participação política das mulheres e igualdade em todos os espaços de poder; desenvolvimento sustentável; direito das mulheres à terra e moradia; cultura, comunicação e mídia não discriminatória; enfrentamento de todas as formas de discriminação, entre elas o racismo, o sexismo e a lesbofobia; e enfrentamento das desigualdades que atingem as mulheres jovens, idosas, em suas especificidades e diversidades (CNPM, 2007. p. 3).
}

Um dos principais avanços da avaliação do I Plano Nacional de Políticas para Mulheres está relacionado à institucionalização da Política Nacional para Mulheres e efetiva implementação dos pontos acordados. Foi incorporada, como resultado da plenária, a temática de raça, etnia e gênero na elaboração do orçamento e no planejamento do Plano. Foram constituídos organismos governamentais estaduais e municipais para coordenação e gerenciamento das políticas para mulheres e conquistados avanços na inclusão da transversalidade do tema gênero em várias políticas públicas. Merecem destaque, também, a promulgação da Lei no. 11.340/2006 (Lei Maria da Penha); a criação de Comissão Tripartite para a Revisão da Legislação Punitiva Contra o Aborto; o aumento de crédito para acesso por parte das mulheres rurais; a política nacional de direitos sexuais e direitos reprodutivos, entre outros (PNPM, 2009).

O II Plano Nacional de Políticas para Mulheres expressou, mais fortemente, o propósito das iniciativas do Governo Federal na reversão das desigualdades de gênero no país. Não se trata de Plano da Secretaria Especial de Políticas para Mulheres (SPM), mas, sim, de instrumento do Governo Federal que traz benefícios tanto para as mulheres quanto para toda a sociedade, através de parâmetros para políticas de igualdade de gênero, focados na realidade vivida pelas mulheres brasileiras (PNPM, 2009). Dessa forma, a SPM assume responsabilidades na liderança, 
sem, contudo, pretender assumir a condição de protagonista exclusiva na efetivação do PNPM. Por essa razão, o próprio PNPM (2009) elenca outros responsáveis, que devem atuar como parceiros na efetivação do que foi acordado em conferências. O Quadro abaixo resume esse entendimento:

Quadro 3 - Institucionalização das políticas de gênero no Poder Executivo federal, estadual e municipal.

\begin{tabular}{|c|c|c|c|c|c|}
\hline Ação & $\begin{array}{l}\text { Órgão } \\
\text { Respons } \\
\text { ável }\end{array}$ & $\begin{array}{c}\text { Programa/ Ação } \\
\text { do PPA }\end{array}$ & Prazo & Produto & Parceiros \\
\hline $\begin{array}{l}\text { Criação de comitês de } \\
\text { gênero em todos os } \\
\text { ministérios e demais } \\
\text { órgãos }\end{array}$ & SPM & $\begin{array}{c}\text { Não } \\
\text { Orçamentária }\end{array}$ & 2011 & $\begin{array}{l}\text { Comitê de } \\
\text { gênero } \\
\text { implantado }\end{array}$ & - \\
\hline $\begin{array}{l}\text { Articulações com os } \\
\text { diversos setores dos } \\
\text { governos estaduais e } \\
\text { municipais }\end{array}$ & SPM & $\begin{array}{c}\text { Não } \\
\text { Orçamentaria }\end{array}$ & 2011 & $\begin{array}{l}\text { Organismo } \\
\text { implantado }\end{array}$ & $\begin{array}{l}\text { Estados e } \\
\text { municípios, } \\
\text { CNDM, } \\
\text { movimentos } \\
\text { feministas e de } \\
\text { mulheres }\end{array}$ \\
\hline $\begin{array}{l}\text { Apoio à criação e ao } \\
\text { fortalecimento de } \\
\text { organismos de } \\
\text { políticas para as } \\
\text { mulheres }\end{array}$ & SPM & $1433 / 8838$ & 2011 & $\begin{array}{l}\text { Encontros } \\
\text { nacionais e } \\
\text { regionais } \\
\text { realizados }\end{array}$ & $\begin{array}{l}\text { Estados e } \\
\text { municípios }\end{array}$ \\
\hline $\begin{array}{l}\text { Realização de } \\
\text { encontros nacionais e } \\
\text { regionais dos } \\
\text { Organismos de } \\
\text { Políticas para } \\
\text { Mulheres }\end{array}$ & SPM & $1433 / 8838$ & 2011 & $\begin{array}{l}\text { Planos } \\
\text { estadual e } \\
\text { municipal } \\
\text { elaborados }\end{array}$ & $\begin{array}{l}\text { Estados, } \\
\text { municípios }\end{array}$ \\
\hline $\begin{array}{l}\text { Apoiar estados e } \\
\text { municípios na } \\
\text { elaboração de planos } \\
\text { locais de políticas para } \\
\text { as mulheres, } \\
\text { conforme diretrizes do } \\
\text { II PMPM. }\end{array}$ & SPM & $1433 / 8838$ & 2011 & $\begin{array}{l}\text { Planos } \\
\text { estadual e } \\
\text { municipal } \\
\text { elaborados }\end{array}$ & $\begin{array}{l}\text { Estados, } \\
\text { municípios, } \\
\text { movimentos } \\
\text { feministas e de } \\
\text { mulheres }\end{array}$ \\
\hline $\begin{array}{l}\text { Elaboração de } \\
\text { estratégia de } \\
\text { divulgação do Plano } \\
\text { Nacional de Políticas } \\
\text { para as Mulheres }\end{array}$ & SPM & $\begin{array}{c}\text { Não } \\
\text { orçamentária }\end{array}$ & 2011 & $\begin{array}{l}\text { Estados e } \\
\text { municípios } \\
\text { com PNPM } \\
\text { divulgado }\end{array}$ & $\begin{array}{l}\text { Estados, } \\
\text { municípios, } \\
\text { CNDM, } \\
\text { movimentos } \\
\text { feministas e de }\end{array}$ \\
\hline
\end{tabular}




\begin{tabular}{|l|l|l|l|l|l|}
\hline & & & & mulheres \\
\hline $\begin{array}{l}\text { Produção e } \\
\text { distribuição de } \\
\text { material de orientação } \\
\text { para que estados e } \\
\text { municípios } \\
\text { elaborarem seus } \\
\text { próprios planos }\end{array}$ & SPM & $0750 / 2000$ & 2011 & $\begin{array}{l}\text { Material } \\
\text { distribuído }\end{array}$ & - \\
\hline $\begin{array}{l}\text { Fomento à promoção } \\
\text { de políticas para as } \\
\text { mulheres, em } \\
\text { estaduais e } \\
\text { municipais, a partir da } \\
\text { transversalidade com } \\
\text { programas, projetos e } \\
\begin{array}{l}\text { ações para jovens e } \\
\text { idosas. }\end{array}\end{array}$ & SPM & Não & 2011 & $\begin{array}{l}\text { Plano } \\
\text { estadual e } \\
\text { municipal } \\
\text { com açória } \\
\text { voltadas a } \\
\text { mulheres, } \\
\text { jovens e } \\
\text { idosas }\end{array}$ & $\begin{array}{l}\text { Secretaria Geral } \\
\text { da República }\end{array}$ \\
\hline
\end{tabular}

Fonte - PNPM (2009).

No que ser refere à implementação do II Plano Nacional de Política para Mulheres, é necessário registrar, demanda parcerias entre os governos federal, estaduais e municipais, e o acompanhamento pela sociedade civil, em especial pelas mulheres, quanto ao processo de elaboração - mediante domínio dos conteúdos em pauta - e execução, através do controle social. Assim, entra em cena a necessidade de as mulheres, por um lado, conhecerem as ações propostas, e, por outro, atuarem como agentes de fiscalização na execução das políticas públicas de relações de gênero, pois, os investimentos e esforços em andamento ganham amplo espaço, no âmbito do Governo Federal, uma vez que dezenove secretarias especiais e ministérios estão trabalhando em parceria para viabilizar a melhoria da qualidade de vida das mulheres brasileiras em toda a sua diversidade (PNPM, 2009).

Foram definidas metas para a gestão e o monitoramento do Plano, dentre elas, a criação e o fortalecimento de organismos estaduais e municipais de promoção de políticas para mulheres nas 27 unidades federativas. Portanto, para que as iniciativas de políticas públicas de gênero ocorram, conforme definições do PNPM, a SPM está fomentando um amplo conjunto de ações de fomento à institucionalização de instrumentos de combate às desigualdades junto às três esferas do Poder Executivo: federal, estadual e municipal (PNPM, 2009). A Secretaria de Políticas para Mulheres tem, nesse sentido, a responsabilidade de coordenar, junto a estados e municípios, o processo de elaboração, implementação e execução das políticas públicas quanto às demandas, necessidades e potencialidades das mulheres, bem como promover, semestralmente, reuniões, em nível nacional, do Fórum de Mecanismos Governamentais de Políticas para Mulheres, com representação das coordenadorias e secretarias de políticas para mulheres de estados e municípios (PNPM, 2009).

Dessa forma, ainda que mediante desafios, em virtude das inovações que trazem as políticas voltadas ao tema das relações e da equidade de gênero, a análise dos dois últimos Planos Plurianuais do Governo Federal (PPA 2004-2007 e PPA 2008-2011) evidencia, na prática, resultados das ações articuladas efetivadas no I e II PNPM, conforme constatou a Organização Internacional do Trabalho (OIT). A inserção de ações junto aos PPAs indica que, pela primeira vez, 
o combate às desigualdades de gênero e raça aparece como objetivo importante dos planos estratégicos de governo, orientando a elaboração do orçamento da União (OIT, 2010).

\section{CONSIDERAÇÕES FINAIS}

As políticas públicas direcionadas à promoção da igualdade de gênero passaram a conquistar espaço, no debate público em nível mundial, a partir de 1975, quando a ONU o reconheceu como Ano Internacional da Mulher. No Brasil, as primeiras iniciativas ocorrem, especialmente, a partir de 2003, tendo como marco principal a criação da Secretaria de Políticas para Mulheres (SPM), órgão vinculado à Presidência da República, que passou a fomentar a criação de instituições dessa natureza em estados e municípios. Na sequência, o processo de articulação e realização da I e II Conferência Nacional de Políticas para Mulheres, nos anos de 2004 e 2007, organizadas pelo governo federal através da SPM, foram responsáveis por criar canais de diálogos e consultas junto a movimentos sociais de mulheres com representação de todos os estados e vários municípios.

As conferências tiveram papel fundamental na elaboração do I e II Plano Nacional de Políticas para Mulheres em consequência dos resultados das discussões ocorridas nos eixos norteadores, voltados à definição de prioridades de políticas públicas a serem implementadas no país, visando à promoção da equidade de gênero. O Governo Federal, a partir dai, incorporou o enfoque de gênero, raça e etnia na formulação e execução do Plano Plurianual (PPA) e do Orçamento Geral da União (OGU), tendo, ainda, o desafio de elaborar o orçamento de maneira a garantir os investimentos necessários para que as políticas públicas voltadas para mulheres, no enfrentamento às desigualdades de gênero, raça e etnia, pudessem se tornar pauta e realidade no Brasil.

O Plano Nacional de Políticas para Mulheres (PNPM), por sua vez, é visto como avanço à valorização da mulher na sociedade brasileira. Ao se analisar tal documento, verifica-se a relevância do pacto de ações, em todos os níveis de governo, no tocante à efetivação de ações, programas e projetos que ganham consequência nos municípios, a partir de medidas que perpassam o poder executivo dos estados. A intervenção nos municípios, portanto, confere visibilidade e efetividade em mudanças na vida das mulheres brasileiras, nas mais diversas regiões do país. Nesse sentido, a institucionalização da Secretaria Especial de Políticas para Mulheres e do I e II Plano Nacional de Políticas para Mulheres (PNPM) foi vital no progresso das intervenções requeridas.

O Plano, como consequência das conferências, é apontado como instrumento de planejamento, execução e acompanhamento das políticas públicas de equidade de gênero, por se tratar de um documento em que o Estado reconhece a pertinência do tema da promoção da igualdade entre homens e mulheres e contempla demandas socialmente pactuadas e entendidas como necessárias. É de responsabilidade do governo central o fomento a ações do PNPM, pois, um dos maiores desafios, relacionados à condição da mulher para os próximos anos, é a superação de circunstâncias de constrangimentos, desigualdades e violências. A superação, então, confirmará pressupostos da Constituição Federal de 1988, que estabelece igualdade nos direitos e obrigações para homens e mulheres.

As ações governamentais, através de políticas públicas e programas desenvolvidos pelo Estado, têm a função de exercer controle e provocar mudanças no quadro de desigualdades hoje constatado. Em primeiro lugar, torna-se necessário que o poder público reconheça que as 
desigualdades existem e que é seu papel fomentar iniciativas para a promoção da equidade de gênero. Em segundo lugar, é factível assumir que é papel do Estado integrar o combate à desigualdade de gênero à agenda de governo, junto com o combate a outras desigualdades. Em terceiro lugar, faz-se necessário planejar estratégias de ação, identificando como e onde as desigualdades se manifestam e quais são seus efeitos, o que exige a articulação dos diversos segmentos da sociedade civil. Por fim, identificar as formas como se dão as desigualdades de gênero, permite identificar prioridades que os governos devem eleger para atuação, a partir do debate público travado e acordos ocorridos em conferencias de âmbito nacional.

\section{REFERÊNCIAS BIBLIOGRÁFICAS}

1. CAROLA, C. R. Dos subterrâneos da história: as trabalhadoras das minas de carvão de Santa Catarina (1937-1964). Florianópolis: UFSC, 2002.

2. CNMP. II Conferência Nacional de Políticas para as Mulheres. Boletim Informativo, n. 1, set., 2007.

3. FARAH, M. F. S. Gênero e políticas públicas. Revista Estudos Feministas, v. 12, n. 1, p. 47-71, jan/abr, 2004.

4. FARIA, N. A divisão sexual do trabalho como base material das relações de gênero. In: SEMPREVIVA ORGANIZAÇÃO FEMINISTA, São Paulo: SOF, 2010.

5. FUJIWARA, L. Governo: substantivo feminino? gênero e políticas públicas em governos subnacionais. Dissertação (Mestrado em Administração Pública e Governo) -

6. FGV-EAESP, São Paulo, 2002.

7. GODINHO, T. Construir a igualdade: combatendo a discriminação. In: Políticas públicas e igualdade de gênero. Cadernos da Coordenadoria Especial da Mulher, n. 8., São Paulo, 2004.

8. HEILBORN, M. L. Gênero: uma breve introdução. In: Gênero e desenvolvimento institucional em ONGs. Rio de Janeiro: IBAM/Instituto de la Mujer, 1995.

9. IBGE. Censo Demográfico 2010, Instituto Brasileiro de Geografia e Estatística, 2012.

10.OIT. Organização Internacional do Trabalho. Igualdade de gênero e raça no trabalho: avanços e desafios. Brasília, 2010.

11.PINTO, G. Mulheres no Brasil: espaço analítico de um plano de políticas públicas para mulheres. In: ENCONTRO NACIONAL DE ESTUDOS POPULACIONAIS, 14., ABEP, Caxambú-MG, 2006.

12.PNPM. Plano Nacional de Políticas para Mulheres. Relatório de Implementação 2005: Plano Nacional de Políticas para as Mulheres. Brasília: 2006.

13. . II Plano Nacional de Políticas para Mulheres. Brasília: 2009.

14.RAGO, M. Feminizar é preciso: por uma cultura filógina. Revista São Paulo em Perspectiva, São Paulo, v. 15, n. 3, 2001.

15.ROCHA, M. B. P. O Movimento de Mulheres em interlocução com o Governo Federal na construção de políticas para a mulher no Brasil (2002-2006). 130 p. Dissertação de Mestrado em Serviço Social - Programa de Pós-Graduação em Serviço Social, Pontifícia Universidade Católica de São Paulo, São Paulo, 2009. 
16.SEPM. Secretaria Especial de Política para Mulheres. Disponível em: <http://www.sepm.gov.br/>. Acesso em: 01 dez. 2012.

17.SOARES, V. Políticas públicas para a igualdade: papel do estado e diretrizes. In: GODINHO, T.; SILVEIRA, M. L. (Orgs.). Políticas públicas e igualdade de gênero. Cadernos da Coordenadoria Especial da Mulher, n. 8. São Paulo, 2004. 